\title{
Virtual welding: A didactic perspective
}

\author{
Steinar Karstensen \& Arne Roar Lier \\ OsloMet - Oslo Metropolitan University, Norway \\ (steinar.karstensen@oslomet.no)
}

\section{Abstract}

This research was conducted as part of a Technical and Vocational Education and Training (TVET) programme in Technical and Industrial Production and is a collaboration between Aas upper secondary school in Akershus and the Department of Vocational Teacher Education at Oslo Metropolitan University (OsloMet). Starting in autumn 2017, simulated welding has been the first step in the use of simulation teaching in order to produce qualified professionals. In TVET education, Virtual Reality technology is a new training tool for welding, and little is known about the pedagogical approaches and didactic challenges.

This article is based on interviews that were conducted with teachers and their immediate supervisors to gain insight into their prior knowledge, the approaches they intended to use, and their initial experiences of the introduction of simulation-based teaching. The research consists primarily of qualitative analyses, based on a phenomenological approach. The focus for the article is the possibilities and limitations of a virtual welding machine, as well as how it might be introduced as an educational and didactic tool in upper secondary school.

The article provides useful knowledge for those who will be using some form of simulation in teaching in general and for simulated welding in particular. This applies to both current TVET teachers and those undergoing Technical and Vocational Teacher Education.

Keywords: simulated welding, technical vocational education and training (TVET), augmented reality (AR), virtual reality (VR), mixed reality, simulation 


\section{Introduction}

In this article, we examine the simulation of welding in a Virtual Reality (VR) machine (what we term VRW - virtual reality welding). VRW encourages exploration and experimentation in learning welding procedures. It allows the user to actively evaluate progress in real time, adjust techniques accordingly and to start over and abandon poor welds without concern for wasted consumable materials.

Research in this field is characterised by a focus on efficiency in education (Stone, Watts \& Zhong, 2011a). This focus is shared by suppliers of VRW machines. They emphasise that a VRW environment can train welders faster and more efficiently, attract and engage learners by making it more enjoyable enhance and supplement welding training, and save money on base materials, electricity, consumables and waste (Stone et al., 2011a; Stone, Watts, Zhong \& Wei, 2011b).

The research is based on empirical evidence regarding decision-making and choice of equipment, placement of the VRW and further developments. We follow how the technical and vocational education and training (TVET) teachers responsible for welding training approach planning and implementation, and how they assess training outcomes. The analysis is based on a phenomenological approach, chosen to illuminate and identify specific phenomena via their perception by the actors in situation (Lester, 1999; Postholm \& Moen, 2009). The primary question concerns the possibilities and limitations of a virtual welding machine, as well as how it might be introduced as an educational and didactic tool in upper secondary school. We look at these issues through the following underlying questions: (1) What are the teacher's reasons and pre-understandings for adopting the virtual welding machine; (2) what are the didactic justifications for how the welding machine is adopted; (3) what is the relationship with the holistic learning approach; and finally, (4) what kind of training is needed to take advantage of the virtual welding machine.

First, we will give a brief introduction to what simulation is, aimed specifically at the use of VRW as a didactic tool in welding training. The article does not deal with welding and welding training, but simulation as a virtual aid used in the training. In this context, it is also important to distinguish between simulated welding through the VRW machine, often referred to as virtual welding, in relation to welding in the real world, or authentic welding, referred to as real welding, although this can also be a practical exercise task undertaken in school.

Previous studies comparing VRW with real welding (Stone et al., 2011a; Stone et al., 2011b) show evidence of the following: VR-integrated training results in superior training outcomes compared to traditional methods (as VR has a higher transfer percentage and a far superior operation completion time than participants in the real welding group), and a VR system leads to increased levels of team interaction and learning. 
There was no difference between the VRW and control groups, in the participants' desires to perform well and to learn from their experience. These results however indicate that participants in the VR group were more willing to communicate and learn from each other. The VR machine provided a conduit by which participants were not only more likely to communicate, but were more likely to value communication and use it to improve their skills. VR Groups were also more likely to seek feedback from the VR system due to the fact that they felt that information given by the system was 'delivered in a more timely manner' than that which could be gained from a shared instructor.

VR integrated technology is significantly less expensive than training using traditional methods. A cost analysis clearly confirms this (Stone et al., 2011a). In additional to material costs, VR machine training makes it possible to practice welds without having to invest time in set-up and material gathering processes. VR training also allows the user to start over and abandon poor welds without concern over wasted consumable materials. These attributes embolden users and encourage exploration of new welding procedures and techniques without the fear of accruing excessive expenses (Stone et al., 2011a; Stone et al., 2011b).

\section{Simulation}

Simulation is the imitation of the operation of a real-world process or system. Simulations can allow learners to practice skills or undertake embodied learning tasks, which is particularly appropriate when the tasks involved are expensive, dangerous or risky to undertake in the real world (Dalgarno \& Lee, 2010). In welding there are high levels of sound, sparks and light which can seem daunting. It is also expensive to train repeatedly to weld correctly.

In this project, we examine the use of a welding simulator that uses both sensors and Mixed Reality (MR). MR is the merging of real and virtual worlds to produce new environments and visualisations in which physical and digital objects co-exist and interact in real time. Mixed reality takes place not solely in the physical or virtual world but entails a combination of reality and Virtual Reality (VR), encompassing both Augmented Reality (AR) and Augmented Virtuality. Whereas VR is a computer technology that uses VR headsets to generate realistic images, sounds and other sensations that simulate a user's physical presence in a virtual or imaginary environment, AR has elements that are 'augmented' by computer-generated or extracted real-world sensory input. Although many forms of simulation deal with MR, it is often referred to as VR, as is the case in this article. (Carl, 2018; Farshid, Paschen, Eriksson \& Kietzmann, 2018).

Simulating reality requires that participants experience a certain amount of realism in the design of the settling, interaction or artefacts in relation to the usage context, so that potential situations can be understood and dealt with more 
quickly when they occur in the field of practice following simulation activity (Spetalen \& Sannerud, 2013, p. 11).

Dalgarno and Lie (2010) explore the distinguishing characteristics of virtual learning environments for VR based on research published within the past two decades. This research is not directly related to VRW machines but is based on general use of 3D environments. We believe this also applies to VRW. Dalgarno and Lie have identified a set of features that include aspects of both representativeness and interactivity. When it comes to representational fidelity, the most important features are: a realistic display of the environment, a smooth display of view changes and object motion, consistency of object behaviour, user representation and spatial audio. Regarding interactivity, they point out different aspects of importance: kinaesthetic and tactile force feedback, embodied actions (including view control, navigation and object manipulation), embodied verbal and non-verbal communication, control of environment attributes and behaviour, and both construction of objects and scripting of object behaviours.

The two most vital visual aspects of the representational fidelity are a realistic display of the environment, and a smooth display of view changes and object motion. Displaying the objects using realistic perspectives and occlusion, as well as realistic textures and lighting, allows for realism that can approach photographic quality. However, even when the images do not approach photographic quality, with sufficient frame rates, the image changes that reflect the viewer's motion or motion of objects can appear smooth enough to provide a realistic experience. In relation to learner interaction, one aspect that is unique to VR is the ability to undertake embodied actions, including view control, navigation and object manipulation (Dalgarno \& Lee, 2010). Furthermore, simulation must lead to a skills transfer and the application of something that one has learned or experienced in one situation over to another situation. Spetalen and Sannerud (2013) note that several factors in the transfer context affect whether simulation is suitable as a transfer strategy. This applies in particular to contextuality, overlapping tasks, an emphasis on the border between simulation contexts and usage contexts, and the extent to which the context of use invokes the use of experiences gained in the simulation context. The extent to which simulation experience is desired, enabled and allowed to be used, has a significant impact on how practice is transferred from simulation activities to final usage context.

Kinaesthetic memory refers to the extent to which the human body can recall its movements and postures. With kinaesthetic development from simulation activities, the experienced action space increases. Consequently, the implementation of simulated practice in the usage context also increases. Minor deviations in participants' experiences as relevant practice in the simulator context can be of great importance for the transfer of practice to the context of use. This may indicate that although the simulation activities are true to nature, relevant practice is 
not transferred unproblematically from a simulation context to a usage context (Spetalen \& Sannerud, 2013).

In welding training, it is fundamental to exercise and train hand and arm movements. Specifically, this means that the quality of a welding string depends on the movement of the welder in terms of the angle between the welding electrode and the workpiece, the speed of the welding electrode and the distance between the electrode and the welding bath. The welding bath is where the welding electrode is melted and binds together, for example, two steel parts. In order to perform approved welds a welding simulator is therefore designed to train users in gesture control (Johansen, 2013).

As it is important to ensure quality in welding, a person can accomplish specific physical movements through the use of sensory-motor learning and the development of kinaesthetic memory. According to previous research and feedback/observations gathered from experts, muscles that are of significant importance to welding performance include the deltoid, trapezius, extensor digitorum and flexor carpi ulnaris. Interviews with 16 professional welders and welding engineers revealed that they believed that sensory-motor learning was a very important component of successful welding. The activation and interactions of the muscles serve to define expert welder control, ability and stability during the commission of a weld (Stone, McLaurin, Zhong \& Watts, 2013). With regard to physical development, (Keir \& MacDonell, 2004) have demonstrated that the activation and interactions of muscles serve to distinguish between expert and novice control, ability and stability throughout the duration of a task.

The results of a study of VR-integrated training showed cognitive development comparable to traditional weld training. In addition, the kinaesthetic memory development in students using VR-integrated weld training was demonstrated to be different to that found in students using traditional weld training, specifically for downhand welding. This difference in kinaesthetic development was a contributing factor in the superior performance outcomes produced by participants in the VR integrated group (Stone et al., 2011b).

\section{VRW machines}

Over the past few years, there have been several types of welding simulators available that have used different simple techniques. More recently however, the combined use of VR and AR makes it possible to train welders without wasting consumables during the learning process. New VR systems can provide visual feedback to the user, indicating proper welding parameters such as travel speed, work angle and arc length (Stone et al., 2011b).

There are several suppliers of VRW machines. Fronius was chosen for this project. Fronius (2019) as a supplier notes that in welding, several consumables (metal, wire, gas, etc.) are normally required, which are expensive due to the 
quantities involved, and that usage of these could easily be reduced in the early stages of learning. They further explain that novice welders could learn basic manual skills using an ergonomically shaped torch, typical workpieces and adjustable parameters, acquiring basic welding knowledge in a play-centred, hands-on manner. Fronius also point out that VR helps to foster group dynamics, as the various tasks can be discussed, practised and solved by trainees working together as a group. They explain that trainees are guided by colour signals true to the optimum welding speed, tip-to work distance and tilt angle they should use for the torch or electrode holder. Trainees will experience direct instant correction during the process. After training, they move on to simulation mode, where they start practising without guiding - with no help from signals. A pedagogically sophisticated points system means that comparable training results can be achieved again and again. Assessment is then made easier by an automatically generated ranking list. Another factor that promotes learning is the playback function. Every single welding operation is recorded and can be played back whenever needed, allowing the welding operation to be analysed accurately (Fronius, 2019).

\section{Methodology}

The context of the research is TVET in Technical and Industrial Production (TIP) at Aas upper secondary school in Akershus (Aas). TIP trains students involved in approximately 90 trades. The first year at TIP entails a wide professional approach and tries to be relevant to all the trades in the education programme. TIP training during the first year of upper secondary school contributes to a broad, technical subject platform, as required in many industries, enabling the more flexible use of labour in these industries. The training helps prevent accidents and injuries by focusing on health, safety and the environment. Joint program subjects emphasise the quality assurance of products, processes and services and familiarises students with the requirements of the workplace. Through training, students develop practical skills, gain professional insight, learn to reflect, and carry out critical assessments. Students learn to interact with others and to work independently in accordance with procedures and drawings, including registration and documentation. Students undergo basic, easy training in all parts of a production process, from planning, production and maintenance to documentation and quality assurance (LK06, 2006).

The stakeholders are Aas as the executive party in this context as well as the chosen supplier, Fronius in this case. The last one is Oslo Metropolitan University (OsloMet), which is both a Technical and Vocational Teacher Education institution in TVET subjects, and a research institution involved in this study.

We had conversations with two teachers and department heads once a month both in in the pre-phase from January to June 2017 and in the testing/ 
implementation phase September 2017 to June 2018. All the meetings were recorded and transcribed. The content of these meetings was thematic, based on three issues: (1) Our feedback and question on reflections from the previous meeting (We have not analysed and categorized the transcribed material every month, but we have looked for changes and developments from meeting to meeting). (2) What experiences the informants have had within the last period. (3) What is planned for the next period.

In addition to the meetings, we used a research log. The TVET teachers were encouraged to write up all their activities in the project. The log read continuously to gain a greater insight into the overall picture of the development work as the teachers experienced it (Hartviksen \& Kversøy, 2008).

The data are based on these conversations, transcriptions and logs. The analysis is based on a phenomenological approach, in order to identify specific phenomena through how they are perceived by the actors in a situation (Lester, 1999; Postholm \& Moen, 2009). In phenomenology, researchers are concerned with the study of experience from the perspective of the individual, 'bracketing' takenfor-granted assumptions and usual ways of perceiving. This becomes a tool for understanding subjective experience, gaining insight into people's motivations and actions, and moving away from assumptions and conventional wisdom. At the same time, it is important to see that epistemological and phenomenological approaches are based on a paradigm of personal knowledge and subjectivity, and thus emphasize the importance of personal perspective and interpretation (Lester, 1999, p. 1).

Phenomenological research can be robust in indicating the presence of factors and their effects in individual cases, but one must be careful not to generalize. The major challenge with phenomenological research is that it generates a large amount of interview notes. The analysis can quickly become messy when the information obtained is complex and difficult to place in neat categories. At the same time there may be many ways to tie the various statements to each other (Lester, 1999, p. 3).

Our research question and underlying question are described in the beginning of the article. It is difficult to draw conclusions in this type of research because it will suggest a finality and assurance that is not defensible. The discussions of the findings can however form the basis for reflection and further work, provided it is made clear what is being done (Lester, 1999).

Before starting the research project, we had only limited insight into VR welding as a technology and learning arena. As we gained insight into the topic of VR welding, the respondents found it interesting to be challenged on the questions we asked. A statement from the respondents substantiates this, 'We become more aware of what we think and do after talking to you.' As researchers, we tried to influence as little as possible with our own concerns, but rather by the participants' own insights. This interaction between respondents and researchers is 
methodically interesting. In a way, researchers are woven into a community where mutual understanding of the research topic is developed together with the participants.

\section{Results}

Before the implementation, the following points were highlighted as advantages, disadvantages and areas of interest, or a combination of these: (1) the placement of the equipment and layout of the VR room, (2) the fact that there is no heat, noise or odour in VRW, (3) there are material savings with VRW, (4) an endless amount of practice is possible with VRW compared to true welding, (5) should VRW come before or after real welding? (6) proper guidance of the welding gun as a basic requirement, and (7) two welds may look the same where an x-ray is needed to see the difference between right and wrong.

As described earlier under simulation and transfer, the similarity between the virtual and the real is important. This was discussed and the decision was made to make a separate glass section in an adjoining room to the workshop due to environmental considerations and the cost of the machine. The glass cage has clear VRW symbols on it, so it is marked as a separate area. Workwear, gloves and safety shoes were purchased as normal HSE equipment used in workshops. A welding mask was also purchased since the one provided with the VRW did not function satisfactorily. VRW training is currently carried out without a real welding mask, but with VR glasses. Here research participants felt there was room for improvement.

The plan was for the teachers to start VRW at the start of the school year in August 2017, but they ended up starting after the autumn holiday. This was due to a busy schedule at the start of the school year and unforeseen events. After starting in November, the teachers' logs indicate that everything worked as intended, see later in this article. Although some minor challenges arose at startup, the teachers dealt with these effectively. The pupils quickly learned from their teachers and were able to perform VRW procedures on their own.

In the conversations we had with the teachers after they had had some experience with the VRW in situ, they expressed that pupils using the VRW machine were far ahead (in terms of the number of exercises) than with the actual realworld welding exercise and that there was a greater student capacity with the VRW machine (the teachers experienced that three students could practice together without compromising capacity).

In the beginning the teachers experienced minor problems but as they become more familiar with the technology, they become adept at solving them. Some teachers mentioned that they initially had operating problems with starting the VRW machine. The simple solution that solved the problem was to re-insert all cables. This is time-consuming and this extra time comes at the expense of 
training time. But this also only happened at the beginning of the start-up and is no longer a problem. The teachers were also curious about whether pupils who showed great aptitude for real welding would demonstrate the same quality in VRW. This prompted the teachers to test a pupil who had welded correctly in the welding boxes. He received almost the highest possible points in VRW on the first try. As mentioned in the method section, we encouraged teachers to write logs so that we could gain insight into everyday use of the VRW machine. Here are a number of excerpts from the logs that we believe show some of the 'little things' that provide insight into the daily experiences:

- [It is] a little annoying to determine where your hand is and what you see in the glasses. The picture in brilliance and reality do not match;

- It is easy to remove the glove and the difference is like night and day;

- The butt weld is not that bad, but the fillet weld is not easy when the guides in the glasses are not visible;

- In the VRW, the students show each other how to do things even when they are competing to achieve the highest score (The score indicates that they have completed the requirement and can progress to the next level) They work better together since they share a VRW. The other students sit in their own welding booth and practice by themselves;

- The pupils compared VRW with their own gaming machines at home and were not impressed by the picture and movement of the VR glasses. But they still find VRW interesting to work with;

- With regard to speed, distance comes before the angle. First with the assistant (teacher), then without, after which the different parameters are adjusted. They struggle with the angles without an assistant. Students get a bit frustrated, so it is advisable to change the score in the assessment system in the VR machine. Lower the requirement for the welding angles, since this is less important in reality.

As some of the excerpts from the logs shows, after that the teachers and students had used the VRW for a while, they could tell us how the systems worked as well as their weaknesses. The teachers explained that in VRW the welding bath where the welding electrode is melted is visually displayed in the VR glasses. At the same time, guides in green, yellow and red are displayed. If the student has all the values within green guides, the quality of the welding is correct. The parameters can be adjusted in the machine. In addition, an assessment system with scores has been added, which says something about goal achievement in the welding exercises. These point systems are derived from gaming technology but can be abstract in terms of both giving concrete feedback to the learner about the accomplishment of the welding skills or a pedagogically informed points system, 
as the supplier of the WRW machine call it (Fronius, 2019). It turns out that this score is highly demanding for certain welds. Based on the small amount of experience already gained, the teachers wanted to correct the reference in the VR programme because the angle of the welding rod in VRW has too little tolerance in relation to ordinary welding. Currently, the scores are based on the teachers' discretion and are equivalent to what is required in relation to real welding exercises.

\section{Discussion}

Changing practice and introducing new learning tools is hard work and requires a considerable amount of will, interest and focus. A collaboration was established between the school, researchers and the supplier that helped focus on VRW and drive the project forward.

Much of the previous research described earlier in this article is American research on laboratory trials. It may be of interest to include this knowledge in the operational aspects of an existing training programme. Economically speaking, VR welding may prove beneficial compared to normal real-life welding training. The teachers involved in the VR welding project calculated that a fillet weld in reality has a unit price of around six euros. Experienced teachers know that students need to practice five to ten times to learn a fillet weld. A corresponding VR fillet weld will cost about 0.10 euros, leading to a didactic question. Is it possible that VR welding can be arranged so that this training can replace traditional welding training?

As a learning tool, the simulator has its limitations. The simulation from the VRW machine provided can be changed. Although it has been difficult, the teachers have undertaken changes to adapt it to the Norwegian model for welding training. What we know about these adaptations is that they involve comprehensive work and that it is necessary to know the VRW machine thoroughly in order to be able to make changes.

Initially, the teachers had an understanding that the simulator training could take place in groups. The teachers also took as a starting point, the simulated sequences that followed with the VR machine which proved to be of little use. These sequences had higher degree of difficulty in relation to the pupils' learning conditions and needs. The welding simulator operates with scores that say something about the skills that students have and must have. A student with little or no welding experience can start at 700-800 points. When they begin to gain some understanding of the flow of the weld, they are at around 1500 points. In order to have sufficient competence or training to weld in reality, students must be between 2500 and 2600 points. Students who can weld before they start TIP have achieved scores of up to 2800 points which means they do not gain anything through training in welding on the simulator. 


\section{Conclusion}

Our main question in this article concerns the possibilities and limitations of a virtual welding machine, as well as how it might be introduced as an educational and didactic tool in upper secondary school. The welding simulator in its original design barely produces the desired learning effects. Based on the experiences teachers had with the welding simulator, they reworked the software to make it suitable for students at VG 1 TIP. After the reprogramming, it has a learning effect on students who have little experience with welding and / or poor motor skills.

The teachers learned that the VRW is not a learning tool for groups, but is more suitable for individual learning. The simulator is self-instructional and provides students with professional feedback on skill progression. The systematic development work done by the teachers in relation to content and progression has contributed to the welding simulator becoming a didactic teaching tool. The teachers describe the welding simulator as a 'teaching assistant'.

In general, the simulated teaching appears to require significant adaptation in order for it to have a didactic approach. Our analysis shows that the welding simulator would have had no value in learning without the systematic testing the teachers have done, adapting the software and its use.

In TVET, simulation is a known approach to learning. Professional didactics 'is about professional competence entailing something more and more than "application" of general theories and theory-based procedures' (Hiim \& Hippe, 2001, p. 39). When VR technology (in our context, VR welding training), is considered as an 'application', it moves away to an even greater extent from the specific 'professional competence'. What kind of professional didactics can be developed in relation to VR learning, or can we describe virtual didactics as a new type of didactics? The simulation that we address here is the first step in gaining an understanding of whether it may be of professional interest to continue working on this topic.

\section{Notes on contributors}

Steinar Karstensen is an Associate Professor at the Department of Vocational Teacher Education at OsloMet - Oslo Metropolitan University, Norway. His area of interest is technology in work and learning. The field of technology and learning focuses on the development of technological competence, digitalisation, automation, robotisation, simulation and relations between technology and learning in different professions, and what implications this has for vocational education in secondary school and for vocational teacher education. He is also the leader of a research group with the same area of interest. 
Arne Roar Lier is an Associate Professor at the Department of Vocational Teacher Education at OsloMet - Oslo Metropolitan University, Norway. His area of interest is linked to learning and work in a broad sense within technological disciplines. In vocational training there is the use of technology in the training with focus on VR/AR and robotisation and what this does with the education related to school and work. His research focus is related to bachelor, master and continuing education at the Department of Vocational Teacher Education at OsloMet. He holds a PhD degree from Roskilde University in Denmark entitled From work to learning. 


\section{References}

Carl, D.R. (2018). The shifting realities of performance improvement: VR, AR, MR. Performance Improvement, 57(4), 6-9.

Dalgarno, B., \& Lee, M.J.W. (2010). What are the learning affordances of 3-D virtual environments? British Journal of Educational Technology, 41(1), 10-32.

Farshid, M., Paschen, J., Eriksson, T., \& Kietzmann, J. (2018). Go boldly! Explore augmented reality (AR), virtual reality (VR), and mixed reality (MR) for business. Business Horizons, 61(5), 657-663.

Fronius. (2019). Virtual welding. Retrieved December, 2019, from https://www.fronius.com/en/welding-technology/world-ofwelding/virtual-welding

Hiim, H., \& Hippe, E. (2001). Å utdanne profesjonelle yrkesutøvere. Oslo: Gyldendal akademisk.

Johansen, H. (2013). Styrkeberegning i sveiseforbindelser statisk. Kompendium/ Høgskolen i Gjøvik, 2012 nr. 3. Retrieved from

http://www.ansatt.hig.no/henningj/materialteknologi/Skriftserien/SB_Sve iseforbindelser-Statisk_2012_nr.3.pdf

Keir, P.J., \& MacDonell, C.W. (2004). Muscle activity during patient transfers: A preliminary study on the influence of lift assists and experience. Ergonomics, 47(3), 296-306.

Lester, S. (1999). An introduction to phenomenological research. Stan Lester Developments, 1-4.

Postholm, M.B., \& Moen, T. (2009). Forsknings- og utviklingsarbeid i skolen: Metodebok for lærere, studenter og forskere. Oslo: Universitetsforlaget.

Spetalen, H., \& Sannerud, R. (2013). Erfaringer med bruk av simulering som transferstrategi. Nordic Journal of Vocational Education and Training, 3(1), 1-17.

Stone, R.T., McLaurin, E., Zhong, P., \& Watts, K.P. (2013). Full virtual reality vs. integrated virtual reality training in welding. Welding Journal, 92(6), 167-174.

Stone, R.T., Watts, K.P., \& Zhong, P. (2011a). Virtual reality integrated welder training. Welding Journal, 90(7), 136-141.

Stone, R.T., Watts, K.P., Zhong, P., \& Wei, C-S. (2011b). Physical and cognitive effects of virtual reality integrated training. Human Factors: The Journal of the Human Factors and Ergonomics Society, 53(5), 558-572. 